\title{
Distance Brought Me Closer
}

\author{
Nicole Hadler ${ }^{1}$ (]) \\ Received: 18 November 2020 / Accepted: 8 December 2020 / Published online: 12 January 2021 \\ (C) Academic Psychiatry 2021
}

The early dismissal from my rotation in the intensive care unit at the beginning of the COVID-19 pandemic confirmed and further strengthened my insecurities I had developed as a medical student - that I was just an extra body, always in the way, never helpful, easily expendable. I felt that in order to rid myself of these insecurities, I should be waking up before sunrise to check on my patients and studying late into the night, even during this pandemic. My only chance at becoming better was to maximize my time spent up close and inperson to get to know my patients, learn about their diseases, and experience their hospital journey alongside them.

Yet, I had no choice but to leave. On March 12, I laid down my stacks of templated notes, EKG printouts, and lab results, placed my stethoscope on my bedroom shelf, and hung up my white coat in the closet. I left the medical campus and returned home, initially continuing to brood over my unfortunate situation even though I knew this change was in place for all the right reasons. How would I learn medicine without being in the physical presence of the doctors, nurses, trainees, and patients? How was I going to decide on a specialty, to discover who I am in the broad and oftentimes intimidating world of medicine, if I could not step foot into the environment where I would spend my career? In no time, my patient notes became outdated and irrelevant, my stethoscope started to collect dust on my shelf, and winter coats and fall jackets buried my white coat deeper into the closet.

It was not long, however, until I realized how much discovery and transformation would occur during my time outside of the hospital. The templated notes and lab printouts no longer obstructed my view. The piercing blares of resident pagers and droning tones of patient monitors no longer overpowered the voices and personalities of my patients or the thoughts and reflections in my head. The white coat

Nicole Hadler

hadlernl@med.umich.edu

1 University of Michigan Medical School, Ann Arbor, MI, USA sleeves no longer blanketed me from the skin-prickling reality of the depths of human suffering and the pinnacles of hope and healing. I quickly learned that taking a step back was equally - if not more - important to my medical education and growth as was donning a short white coat or listening to a heart murmur. I could more clearly see, hear, and feel for my patients and their needs, and I could hear and discover myself.

During the 10 weeks I spent away from the medical campus, I received the precious gifts of time and distance to sit alone with my thoughts, to replay my most salient experiences in medicine, to learn from my mistakes. But it wasn't the CT scans, the sepsis workups, the multi-drug-resistant pneumonias, or the "zebra" cases that I revisited. Rather, I was rewatching my attending's discussion of an elderly woman's poor prognosis to her sleep-deprived, shell-shocked son who had spent weeks in the hospital alongside her. I was recalling with awe the power of faith and family cohesion in a woman's resilience and optimism during her battle with lung cancer. I was re-playing my conversation with a terrified young man who had just been told that he needed a heart surgery, mulling over my missed opportunities to comfort and reassure, picking apart the sentences that I could have rephrased, and the moments when I could have offered a kind touch or smile.

From these reflections, I realized that throughout my short medical journey, I had been most present and attentive during the intimate conversations with my patients, when they placed their trust in me and opened up about their deepest fears, darkest traumas, and hopes for the future. Furthermore, I realized that I had been taking for granted what a privilege it is to be invited into someone's personal narrative and bear witness to their struggles and triumphs. I discovered that my place in medicine would be to listen to and support these patients during their mental and emotional hardships as their psychiatrist. My interest in this specialty had been at the back of my mind for a while, but I finally had the space to bring it to the front.

I never imagined that during an unprecedented period of illness in our society and abrupt and widespread changes to plans and schedules, I would draw closer to and become more confident in my vision for the future, and I would become 
fully devoted to my specialty. A little bit of distance from my training afforded me the time and freedom to pause, take a breath, step back, and reflect on why I chose medicine. I had the extraordinary opportunity to look back at my training and growth and begin to map out the role that I want to play in the field of medicine. I was no longer an extra body in the hospital; I was a future psychiatrist in training.

As trainees, we have had an important role to play both during the early stages of the pandemic and now that we are back on the wards, and it does not necessarily entail wearing a white coat, spending late nights in the library, or participating in early morning rounds. We must reflect, grow, look ahead, and envision how we can make a difference in the field of medicine. From a distance, we gain clarity that we would not otherwise experience from our view on the hospital floor and with the weight of patient notes, stethoscopes, white coats, and exams. An exam does come after the pandemic, however. This exam is lifelong - to use our private reflections and experiences in medicine and during the pandemic to guide how we learn, how we practice, how we treat our patients, and how we will make this world a better place.

\section{Compliance with Ethical Standards}

Conflict of Interest The author states that there is no conflict of interest.

Publisher's Note Springer Nature remains neutral with regard to jurisdictional claims in published maps and institutional affiliations. 